\title{
Uji Kemampuan Adsorpsi Arang Batok Kelapa Pada Efluen Instalasi Pengolahan Air Limbah Industri Pertambangan Iodium Menggunakan Parameter COD Secara Batch
}

\author{
Faizal Shah Alam dan Mohammad Razif \\ Departemen Teknik Lingkungan, Fakultas Teknik Sipil, Lingkungan, dan Kebumian, Institut Teknologi \\ Sepuluh Nopember (ITS) \\ e-mail:razif@its.ac.id
}

\begin{abstract}
Abstrak-Dalam proses produksi industri pertambangan iodium, dihasilkan limbah cair yang dibuang ke Instalasi Pengolahan Air Limbah (IPAL). Dalam setahun terakhir, terdapat ganggang pada air limbah industri pertambangan iodium. Adanya ganggang merupakan indikasi bahwa zat pencemar pada air limbah belum tereduksi dengan baik sehingga tidak aman apabila dibuang langsung ke lingkungan. Oleh karena itu, diperlukan suatu metode untuk mereduksi zat pencemar yang efisien dan inovatif. Salah satunya yaitu adsorpsi menggunakan arang batok kelapa. Tujuan dari penelitian ini yaitu menentukan nilai efisiensi removal adsorben arang batok kelapa pada parameter COD dan nilai adsorpsi isotermisnya menggunakan analisis jartest secara batch. Hasil penelitian pada analisis adsorpsi secara batch didapat bahwa efisiensi removal COD menggunakan arang batok kelapa sebesar 28,13 - 53,13 \% dengan nilai kinetika adsorpsinya masing-masing sebesar $(1-9) \times 10^{-4} \mathrm{mg} \mathrm{COD} \mathrm{/} \mathrm{mg}$ adsorben. Konsentrasi air limbah, ukuran butiran adsorben, dan massa adsorben optimum dari sistem batch adalah 50\%, diameter mesh 12, dan 12,5 gr/L.
\end{abstract}

Kata Kunci-Adsorpsi, Air Efluen IPAL Industri Pertambangan Iodium, Arang Batok Kelapa, Isoterm, Karbon Akrif.

\section{PENDAHULUAN}

$\mathbf{I}_{b}^{\mathrm{N}}$ NDUSTRI pertambangan iodium merupakan industri yang bergerak di bidang pertambangan iodium dan pengolahannya serta industri obat formulasi. Industri ini merupakan industri yang menggunakan produk hasil tambangnya menjadi produk obat jadi dan telah berlangsung sejak tahun 1994. Dalam proses produksi tersebut, dihasilkan limbah cair yang dibuang ke Instalasi Pengolahan Air Limbah (IPAL).

Setahun terakhir, di dalam Instalasi Pengolahan Air Limbah (IPAL) tersebut, terdapat ganggang pada air limbah yang diproses di dalam IPAL tersebut sehingga menyebabkan beberapa nilai paramater mendekati nilai ambang batas yang ditetapkan oleh Peraturan Gubernur Jawa Timur Nomor 52 Tahun 2014 [1]. Adanya ganggang merupakan indikasi bahwa limbah tersebut masih mengandung zat pencemar sehingga tidak aman apabila dibuang langsung ke lingkungan. Apabila air olahan limbah tersebut akan dibuang ke lingkungan, maka air olahan limbah tersebut harus aman dan tidak mengandung zat pencemar berbahaya bagi lingkungan dan masyarakat sekitar industri tersebut.

Berbagai upaya yang dapat dilakukan untuk mereduksi zat pencemar yang terdapat pada air limbah industri tersebut adalah dengan penambahan tawas dan pemberian filter batu apung pada IPAL industri tersebut. Namun, cara tersebut kurang efektif dalam mereduksi zat pencemar. Oleh karena itu, diperlukan suatu sistem pereduksian zat pencemar yang berskala kecil, ekonomis, efektif, dan inovatif, yaitu dengan metode adsorpsi menggunakan arang aktif. Adsorpsi merupakan suatu proses penyerapan oleh suatu padatan terhadap suatu zat yang terjadi pada permukaan zat padat karena adanya gaya tarik atom atau molekul pada permukaan zat padat tanpa meresap ke dalam [2]. Sedangkan, arang aktif dapat dibuat dengan mengaktivasi berbagai macam jenis arang, salah satunya menggunakan batok kelapa. Apabila ditinjau keberadaannya, batok kelapa sangat mudah ditemukan. Selain keberadaannya, batok kelapa belum dimanfaatkan sepenuhnya untuk kegiatan produktif yang dapat meningkatkan nilai tambahnya sehingga berpotensi digunakan sebagai alternatif bahan baku adsorben zat pencemar. Dari metode ini, diharapkan zat pencemar dapat direduksi sehingga hasil olahan air limbah industri tersebut aman apabila akan dibuang ke lingkungan dan dapat meningkatkan nilai produksi pada industri pertambangan iodium.

\section{METODE PENELITIAN}

\section{A. Prosedur Penelitian}

Analisis karakteristik air limbah industri pertambangan iodium

Analisis ini dilakukan dengan cara mengambil data eksisiting hasil pengukuran COD pada air limbah di IPAL Industri Pertambangan Iodium dan dibandingkan dengan baku mutu Peraturan Gubernur Jawa Timur Nomor 52 Tahun 2014 [1]. Hal ini dilakukan agar mengetahui kadar air limbah industri pertambangan iodium. 


\section{Uji Ketahanan Fisik dan Densitas Arang Batok Kelapa}

Adsorben yang digunakan dalam percobaan ini adalah arang batok kelapa yang diperoleh dari industri pertambangan iodium yang terletak di Kabupaten Jombang. Sebelum digunakan dalam percobaan, maka dilakukan uji ketahanan fisik media dan uji densitas media.

Uji ketahanan fisik arang batok kelapa bertujuan untuk mengetahui pengurangan berat media setelah dilakukan perendaman dengan larutan asam [3]. Kelayakan fisik arang batok kelapa terpenuhi jika pengurangan berat media tidak lebih dari $2 \%$ berat media mula-mula. Langkah-langkah uji ketahanan fisik [4] yaitu:

a. Ditimbang 10 gram media adsorben yang telah diayak dan telah disimpan dalam oven $105{ }^{\circ} \mathrm{C}$ sebagai berat bersih mula-mula.

b. Media direndam dalam larutan asam selama 24 jam.

c. Ditiriskan dan dikeringkan dalam oven $105^{\circ} \mathrm{C}$ selama 24 jam.

d. Media ditimbang sebagai berat kering akhir.

Sedangkan, uji densitas arang batok kelapa bertujuan untuk mengetahui berat volume arang batok kelapa dalam mengadsorpsi air limbah industri pertambangan iodium. Pengujian ini menggunakan metode Apparent Density dan True Bulk Density [5]. Apparent Density merupakan berat jenis bahan media kondisi kering. Sedangkan, True Bulk Density merupakan berat jenis media pada keadaan jenuh air. Prosedur pelaksanaan Apparent Density [3] yaitu:

a. Dimasukkan media adsorben yang telah dikeringkan sebanyak kira-kira $50 \mathrm{ml}$ ke dalam gelas ukur $100 \mathrm{ml}$.

b. Dipadatkan media sampai $50 \mathrm{ml}$ dengan cara ditekan bagian permukaan medianya.

c. Dikeluarkan media dari dalam gelas ukur dan ditimbang beratnya.

d. Apparent Density akan diketahui menggunakan persamaan (1).

PAD $(\mathrm{gram} / \mathrm{ml})=$ Berat Kering Karbon $/ 50 \mathrm{ml}$

Sedangkan, prosedur pelaksanaan True Bulk Density [3] yaitu:

a. Ditimbang 50 gram media yang telah dikeringkan

b. Dimasukkan dalam gelas beker dan direndam media dengan air suling. Untuk menghilangkan gelembung-gelembung udara yang terperangkap, dilakukan dengan pemanasan atau pendidihan, pengadukan, dan pengetukan.

c. Setelah dingin, dilakukan pemisahan media dengan air.

d. Dilakukan penimbangan terhadap media basah tersebut sebagai P gram.

e. Dimasukkan media yang telah berisi $100 \mathrm{ml}$ air suling.

f. Volume yang terjadi dibaca sebagai $\mathrm{V} \mathrm{ml}$.

g. Mendapatkan true bulk density menggunakan persamaan (2).

$$
\text { PTd }(\mathrm{gram} / \mathrm{ml})=50 /(\mathrm{V}-\mathrm{P}-50)
$$

\section{Percobaan pendahuluan}

Percobaan pendahuluan dilakukan untuk mengetahui massa adsorben, waktu pengadukan, dan kecepatan pengadukan optimum. Analisis penentuan massa adsorben dilakukan dengan proses batch. Proses ini memvariasikan massa sebesar 50 gram, 100 gram, dan 150 gram pada $250 \mathrm{ml}$ sampel dengan kecepatan putaran $60 \mathrm{rpm}$ selama 3 jam. Langkah-langkah prosedurnya yaitu:

1. Siapkan 3 buah gelas beker ukuran 1 Liter

2. Isi gelas beker dengan massa yang telah ditentukan

3. Tuangkan $250 \mathrm{ml}$ air limbah industri pertambangan iodium ke dalam gelas beker tersebut.

4. Atur kecepatan pengadukan pada 60 rpm selama 3 jam.

5. Setelah 3 jam, hentikan pengadukan. Kemudian, tunggu beberapa saat hingga partikel-partikel makro mengendap selama 30 menit.

6. Ambil supernatant pada masing-masing gelas beker untuk dianalisis COD-nya.

7. Massa optimum, yang akan digunakan, ditentukan berdasarkan hasil analisis COD-nya.

Penentuan waktu pengadukan dilakukan dengan membubuhkan massa adsorben optimum pada kecepatan pengadukan $60 \mathrm{rpm}$ dan dilakukan analisis warna dan PV pada interval 30 menit. Langkah-langkah prosedurnya yaitu:

1. Siapkan 3 buah gelas beker ukuran 1 Liter.

2. Tuangkan air limbah industri pertambangan iodium pada masing-masing gelas beker hingga mencapai $500 \mathrm{ml}$.

3. Tuangkan massa optimum adsorben pada masing-masing gelas beker.

4. Atur gelas beker pada jartest. Kemudian, jalankan alat pengadukan pada kecepatan $60 \mathrm{rpm}$.

5. Setelah mencapai waktu pengadukan yang ditentukan dengan interval 30 menit ( 2 jam, 2,5 jam, 3 jam). Ambil supernatant pada masing-masing gelas beker untuk dilakukan analisis COD-nya.

6. Waktu optimum, yang akan digunakan, ditentukan berdasarkan hasil analisis COD-nya.

Penentuan kecepatan pengadukan atau agitasi dilakukan dengan massa optimum dan waktu pengadukan yang didapat pada penentuan massa adsorben dan penentuan waktu pengadukan. Variasi kecepatan yang digunakan adalah $60 \mathrm{rpm}$, $80 \mathrm{rpm}$, dan $100 \mathrm{rpm}$. Langkah-langkah prosedurnya yaitu:

1. Siapkan 1 buah gelas beker ukuran 1 Liter.

2. Tuangkan air limbah industri pertambangan iodium pada gelas beker hingga mencapai volume $500 \mathrm{ml}$.

3. Tuangkan massa optimum adsorben pada gelas beker.

4. Atur gelas beker pada jartest. Kemudian, jalankan alat tersebut pada kecepatan pengadukan 60 rpm dengan waktu pengadukan optimum.

5. Setelah tercapai waktu pengadukan optimumnya, hentikan pengadukan selama 30 menit, dan diambil supernatant-nya.

6. Dilakukan analisis COD pada supernatant tersebut.

7. Ulangi prosedur percobaan 1-6 pada kecepatan pengadukan $80 \mathrm{rpm}$ dan $100 \mathrm{rpm}$.

8. Kecepatan pengadukan optimum, yang akan digunakan, ditentukan berdasarkan hasil analisis COD-nya.

Analisis adsorpsi dengan sistem batch

Variabel pada analisis adsorpsi dengan sistem batch yaitu ukuran arang batok kelapa (mesh 8 , mesh 10 , mesh 12), massa butiran arang batok kelapa (q2,5 gr, $25 \mathrm{gr}$, dan 50 gr), dan konsentrasi air limbah industri pertambangan iodium (100\%, 75\% dan 50\%). Diagram kerja adsorpsi secara batch disajikan pada Gambar 1. Analisis ini menggunakan alat jartest sebagai 
pengaduk. Kecepatan pengadukan, waktu pengadukan, dan massa adsorben yang digunakan adalah kecepatan pengadukan, waktu pengadukan, dan massa adsorben yang telah dilakukan percobaan pendahuluan sehingga didapat nilai optimumnya. Selanjutnya, langkah-langkah analis is ini yaitu:

a. Menyiapkan 4 gelas beker ukuran 1 Liter yang telah dibersihkan

b. Menyiapkan air limbah industri pertambangan iodium dengan konsentrasi $100 \%, 75 \%$, dan $50 \%$.

c. Gelas beker diisi masing-masing air limbah industri pertambangan iodium sampai $500 \mathrm{ml}$ dengan rincian 1 gelas beker untuk 1 konsentrasi.

d. Gelas beker sisanya diisi dengan aquades sampai $500 \mathrm{ml}$ sebagai blanko.

e. Diletakkan gelas beker tersebut pada alat jartest.

f. Dimasukkan adsorben sebanyak massa optimum yang didapat dari hasil percobaan pendahuluan menggunakan ukuran media mesh $8(3,35-2,36 \mathrm{~mm})$. pada 3 gelas beker yang berisi air limbah industri pertambangan iodium, dan 1 gelas beker yang berisi aquades tanpa adsorben sebagai kontrol.

g. Dijalankan alat jartest dengan kecepatan putaran dan waktu pengadukan yang didapat pada percobaan pendahuluan.

h. Setelah dicapai waktu pengadukan dan didiamkan selama 30 menit, dilakukan pengambilan sampel supernatant dari tiap gelas beker.

i. Dilakukan analis is COD pada masing-masing sampel.

j. Diulangi langkah a sampai j untuk ukuran media mesh 10 (2,36-2,00 mm) dan ukuran media mesh 12 (2,00-1,63 mm).

Konsentrasi Air Limbah Industri Pertambangan Iodium

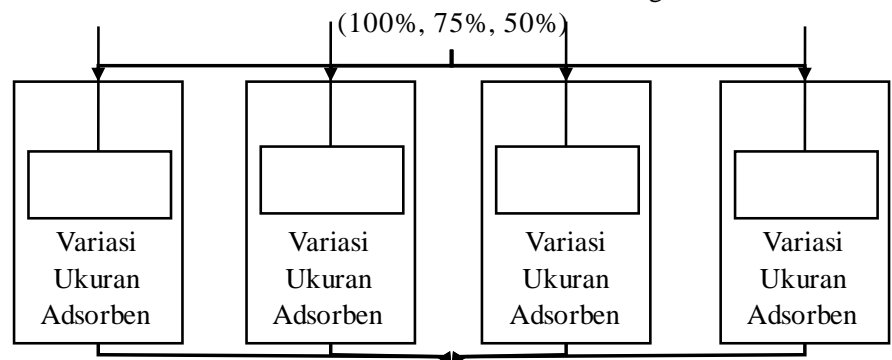

Aduk dengan kecepatan pengadukan dan waktu pengadukan serta massa adsorben yang diperoleh dari penelitian terdahulu. $\downarrow$

Analisis COD

Gambar 1. Skema Percobaan Pada Sistem Adsorpsi Secara Batch

\section{HASIL DAN DISKUSI}

\section{A. Uji Pendahuluan}

Uji Densitas dan Ketahanan Fisik Arang Batok Kelapa

Analisis pertama yaitu uji densitas arang batok kelapa. Metode yang digunakan pada uji densitas ini adalah metode apparent density dan true bulk density. Hasil uji densitas yang disajikan pada Tabel 1 menunjukkan bahwa nilai densitas pada diameter mesh 12 paling besar daripada diameter mesh lainnya. Hal ini dikarenakan bahwa semakin besar diameter mesh adsorben, maka pori pada adsorben akan semakin kecil juga sehingga nilai massa volume akan semakin besar.
Tabel 1.

Hasil Analisis Densitas Media dengan Metode Apparent Density dan True Bulk Density

\begin{tabular}{lcc}
\hline \hline Diameter & Apparent Density $(\mathrm{gr} / \mathrm{ml})$ & True Bulk Density $(\mathrm{gr} / \mathrm{ml})$ \\
\hline Mesh 8 & 0,5573 & 1,1163 \\
Mesh 10 & 0,6507 & 1,7060 \\
Mesh 12 & 0,6589 & 1,7097 \\
\hline \hline
\end{tabular}

Analisis kedua yaitu dilakukan uji ketahanan fisik dari arang batok kelapa. Dari pengujian tersebut, didapat hasil uji ketahanan fisik arang batok kelapa yang disajikan pada Tabel 2. Hasil pengujian tersebut menunjukkan bahwa semua jenis ukuran arang batok kelapa terjadi penurunan berat sebesar 8-9 $\%$ setelah direndam asam kuat $(\mathrm{HCl})$ dan pemanasan menggunakan oven $105{ }^{\circ} \mathrm{C}$ selama 24 jam. Persentase nilai massa arang batok kelapa hasil pengujian lebih kecil dari $10 \%$ menunjukkan bahwa arang batok kelapa layak untuk digunakan sebagai adsorben.

Tabel 2.

Hasil Analisis Uji Ketahanan Fisik Media

\begin{tabular}{lccc}
\hline \hline Diameter & $\begin{array}{c}\text { Massa Media } \\
\text { Awal (gr) }\end{array}$ & $\begin{array}{c}\text { Massa Media } \\
\text { Akhir (gr) }\end{array}$ & $\begin{array}{c}\text { Persentase } \\
\text { Kehilangan Massa } \\
(\%)\end{array}$ \\
\hline Mesh 8 & 10,0007 & 9,0844 & 9,16 \\
Mesh 10 & 10,0014 & 9,0571 & 9,44 \\
Mesh 12 & 10,0010 & 9,1630 & 8,38 \\
\hline \hline
\end{tabular}

Analisis karakteristik air limbah

Analisis ketiga pada penelitian ini adalah analisis karakteristik air limbah industri pertambangan iodium. Pada analisis ini, dilakukan pengambilan data sekunder dengan cara mendata hasil pengukuran COD pada influen dan efluen air limbah di instalasi pengolahan air limbah (IPAL) industri pertambangan iodium yang hasilnya disajikan pada Tabel 3 . Setelah didapat data tersebut, dilakukan perbandingan antara data hasil pengukuran COD air limbah di IPAL industri pertambangan iodium analisis dengan baku mutu Peraturan Gubernur Jawa Timur Nomor 52 Tahun 2014 [1].

Tabel 3.

Data Analisis IPAL Industri Pertambangan Iodium Bulan Oktober 2015

\begin{tabular}{cccc}
$\begin{array}{c}\text { Waktu } \\
\text { Pengukuran }\end{array}$ & $\begin{array}{c}\text { Inlet } \\
\text { IPAL }\end{array}$ & $\begin{array}{l}\text { Outlet } \\
\text { IPAL }\end{array}$ & $\begin{array}{c}\text { Baku Mutu Air } \\
\text { Limbah untuk } \\
\text { Industri Farmasi [1] }\end{array}$ \\
\hline \hline Oktober 2015 & 292,70 & 285,60 & \\
& & 217,90 & \\
November 2015 & 296,80 & & \\
& & 56,38 & \\
Desember 2015 & 126,20 & & \\
& & 51,55 & \\
Januari 2016 & 169,80 & 131,90 & \\
Februari 2016 & 356,50 & 107,40 & \\
Maret 2016 & 605,30 & 45,41 & \\
April 2016 & 278,10 & 242,80 & \\
\hline Mei 2016 & 324,20 & 126,60 & \\
Juni 2016 & 259,80 &
\end{tabular}

Tabel 3 menunjukkan bahwa data hasil analisis air limbah pada outlet IPAL industri pertambangan iodium telah 
memenuhi baku mutu Peraturan Gubernur Jawa Timur Nomor 52 Tahun 2014. Namun, hasil analisis air limbah pada inlet IPAL industri pertambangan iodium melebihi nilai baku mutu yang ditetapkan oleh Peraturan Gubernur Jawa Timur Nomor 52 Tahun 2014 [19].

Penentuan Massa Adsorben

Analisis keempat yaitu analisis adsorpsi dengan sistem batch menggunakan jartest untuk menentukan massa optimum adsorben. Hasil analisis tersebut disajikan pada Tabel 4. Berdasarkan Tabel 4, massa yang paling optimum adalah massa sebesar 12,5 gram dengan nilai persentase optimum dari parameter COD sebesar 17,39\%. Hal ini dikarenakan faktor adsorben yang menghasilkan abu saat proses pengadukan di dalam jartest sehingga mengganggu pembacaan.

Tabel 4.

Hasil Analisis Variasi Massa Adsorben Menggunakan Jartest

\begin{tabular}{lccccccc}
\hline \hline & \multicolumn{3}{c}{ Variasi Massa (gram) } & \multicolumn{4}{c}{ Persentase Removal (\%) } \\
Parameter & 0 & 12,5 & 25 & 50 & $\begin{array}{c}12,5 \\
\text { gram }\end{array}$ & $\begin{array}{c}25 \\
\text { gram }\end{array}$ & $\begin{array}{c}50 \\
\text { gram }\end{array}$ \\
\hline $\begin{array}{l}\text { COD } \\
(\mathrm{mg} / \mathrm{L})\end{array}$ & 23,00 & 19,00 & 19,01 & 19,02 & 17,39 & 17,35 & 17,30 \\
\hline \hline
\end{tabular}

Penentuan waktu pengadukan

Analisis kelima yaitu analisis adsorpsi dengan sistem batch menggunakan jartest untuk menentukan waktu pengadukan optimum sehingga adsorben dapat meng-adsorpsi adsorbat hingga mencapai batas maksimal. Hasil dari analisis ini disajikan pada Tabel 5. Tabel 5 menunjukkan bahwa waktu pengadukan selama 180 menit atau 3 jam memiliki efisiensi removal yang tinggi.

Tabel 5.

Hasil Analisis Variasi Waktu Pengadukan Menggunakan Jartest

\begin{tabular}{cc}
\hline \hline Waktu (menit) & COD $(\mathrm{mg} / \mathrm{L})$ \\
\hline 0 & 23 \\
30 & 29 \\
60 & 23 \\
90 & 23 \\
120 & 20 \\
150 & 16 \\
180 & 15 \\
210 & 18 \\
\hline \hline
\end{tabular}

Penentuan kecepatan pengadukan

Analis is keenam yaitu analisis adsorpsi dengan sistem batch menggunakan jartest untuk menentukan kecepatan pengadukan optimum sehingga adsorben dapat meng-adsorpsi adsorbat hingga mencapai batas maksimal. Hasil dari analisis ini disajikan pada Tabel 6. Tabel 6 menunjukkan bahwa kecepatan pengadukan yang optimum adalah $50 \mathrm{rpm}$. Apabila kecepatan pengadukan kurang dari $50 \mathrm{rpm}$, didapatkan efisiensi removal menurun akibat agitasi yang dilakukan terlalu kecil.

Tabel 6.

Hasil Analisis Variasi Kecepatan Pengadukan Menggunakan Jartest

\begin{tabular}{cc}
\hline \hline Kecepatan Pengadukan $(\mathrm{rpm})$ & COD $(\mathrm{mg} / \mathrm{L})$ \\
\hline 0 & 24 \\
40 & 23 \\
50 & 21 \\
60 & 24 \\
\hline \hline
\end{tabular}

\section{B. Analisis Adsorpsi dengan Sistem Batch}

Analisis kedelepan yaitu analisis adsorpsi secara batch menggunakan jartest untuk menentukan konsentrasi air limbah dan ukuran media adsorben optimum sehingga adsorben dapat meng-adsorpsi adsorbat hingga mencapai batas maksimal. Hasil analisis adsorpsi secara batch dengan parameter COD disajikan pada Gambar 2.

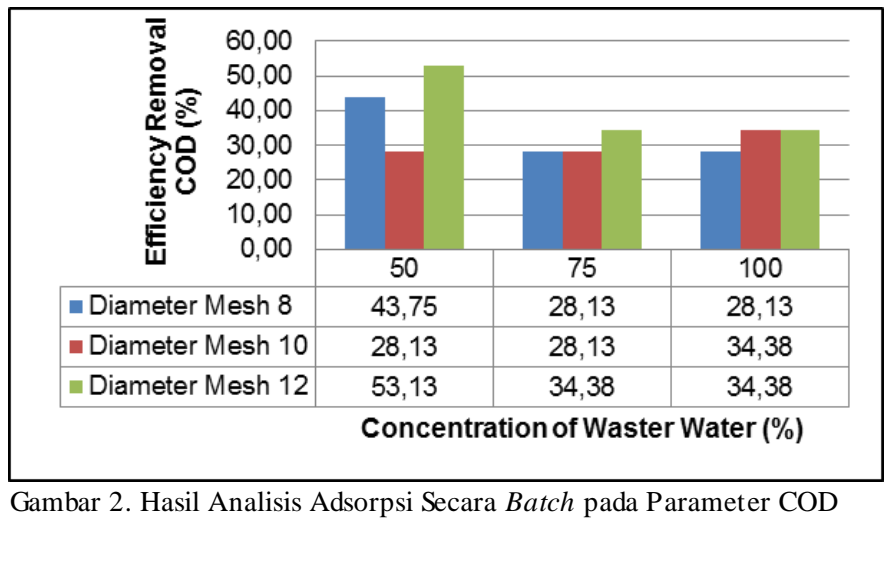

Gambar 2 menunjukkan bahwa semakin besar konsentrasi air limbah industri pertambangan iodium, maka rentang efisiensi removal COD yang didapat semakin kecil kecuali adsorben diameter mesh 10 yang terjadi peningkatan. Rentang efisiensi yang didapat dari konsentrasi air limbah 50\%, 75\%, dan $100 \%$ masing-masing adalah 28,13-53,13\%, 28,13-34,38\%, dan 28,13$34,38 \%$. Berdasarkan ukuran diameter adsorbennya, tren efisiensi removal warna menunjukkan bahwa terjadinya penurunan nilai efisiensi removal warna seiring meningkatnya konsentrasi air limbah. Dengan demikian, nilai efisiensi removal warna paling baik didapat dari adsorben berdiameter mesh 12 dengan konsentrasi air limbah sebesar 50\%.

\section{Adsorpsi Isothermis pada Parameter COD}

Dalam penentuan kapasitas adsorpsi arang batok kelapa, digunakan persamaan isoterm dengan melakukan plot data hasil analisis COD. Persamaan isoterm yang digunakan yaitu persamaan Isoterm Langmuir. Hasil persamaan tersebut akan digunkanan berdasarkan nilai regresi yang paling linier, yaitu nilai konstanta mendekati satu (1). Perhitungan isoterm dimaksudkan untuk melihat kecenderungan data yang diperoleh dari isoterm tersebut. Untuk mengetahui kecenderungan itu, maka nilai regresi dari isoterm tersebut akan dibandingkan.

\section{Isoterm Langmuir}

Kemampuan adsorpsi arang batok kelapa menggunakan isoterm Langmuir ditentukan dengan menghubungkan antara konsentrasi akhir (Ce) dan massa arang batok kelapa. Contoh dan hasil perhitungan isoterm Langmuir arang batok kelapa berdiameter mesh 8,10 , dan 12 pada parameter warna disajikan pada Tabel 7 hingga Tabel 9.

Keterangan:

Co : Konsentrasi COD Awal (mg/L)

$\mathrm{Ce}:$ Konsentrasi COD Akhir $(\mathrm{mg} / \mathrm{L})$

$\mathrm{V}$ : Volume Larutan (L)

m : Massa Arang Batok Kelapa (mg/L) 
$\mathrm{x} \quad$ : COD Ter-adsorp (mg/L)

x/m : COD Ter-adsorp / Massa Arang Batok Kelapa

Contoh perhitungan:

Diketahui pada diameter mesh 8 dan konsentrasi air limbah 100 $\%$

$\mathrm{m}=12.500 \mathrm{mg} / \mathrm{L}$

$\mathrm{Co}=24 \mathrm{mg} / \mathrm{L}$

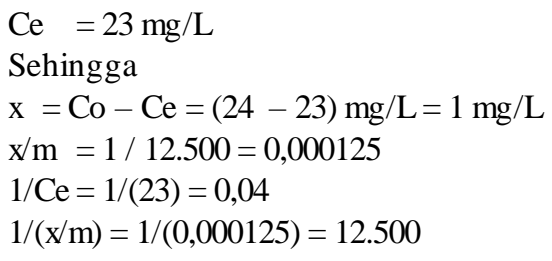

Sehingga

$\mathrm{x}=\mathrm{Co}-\mathrm{Ce}=(24-23) \mathrm{mg} / \mathrm{L}=1 \mathrm{mg} / \mathrm{L}$

$\mathrm{x} / \mathrm{m}=1 / 12.500=0,000125$

$1 /(\mathrm{x} / \mathrm{m})=1 /(0,000125)=12.500$

Tabel 7.

Perhitungan Isoterm Langmuir Arang Batok Kelapa Berdiameter Mesh 8

\begin{tabular}{|c|c|c|c|c|c|c|c|c|c|}
\hline $\begin{array}{c}\text { Konsentrasi Air Limbah } \\
(\%)\end{array}$ & $\begin{array}{l}\text { Massa Adsorben } \\
\text { (gr) }\end{array}$ & Co $(\mathrm{mg} / \mathrm{L})$ & $\mathrm{Ce}(\mathrm{mg} / \mathrm{L})$ & V (L) & $\begin{array}{c}\mathrm{m} \\
(\mathrm{mg} / \mathrm{L})\end{array}$ & $\mathrm{x}(\mathrm{mg} / \mathrm{L})$ & $\mathrm{x} / \mathrm{m}$ & $1 / \mathrm{Ce}$ & $1 /(\mathrm{x} / \mathrm{m})$ \\
\hline 100 & 12,5 & 32 & 23 & 1 & 12500 & 9 & 0,0007 & 0,04 & $1.388,89$ \\
\hline 75 & 12,5 & 32 & 23 & 1 & 12500 & 9 & 0,0007 & 0,04 & $1.388,89$ \\
\hline
\end{tabular}

Tabel 8.

Perhitungan Isoterm Langmuir Arang Batok Kelapa Berdiameter Mesh 10

\begin{tabular}{|c|c|c|c|c|c|c|c|c|c|}
\hline $\begin{array}{c}\text { Konsentrasi Air Limbah } \\
(\%)\end{array}$ & $\begin{array}{l}\text { Massa Adsorben } \\
\text { (gr) }\end{array}$ & Co $(\mathrm{mg} / \mathrm{L})$ & $\mathrm{Ce}(\mathrm{mg} / \mathrm{L})$ & $\mathrm{V}(\mathrm{L})$ & $\begin{array}{c}\mathrm{m} \\
(\mathrm{mg} / \mathrm{L})\end{array}$ & $\mathrm{x}(\mathrm{mg} / \mathrm{L})$ & $\mathrm{x} / \mathrm{m}$ & $1 / \mathrm{Ce}$ & $1 /(\mathrm{x} / \mathrm{m})$ \\
\hline 75 & 12,5 & 32 & 23 & 1 & 12500 & 9 & 0,0007 & 0,04 & $1.388,89$ \\
\hline
\end{tabular}

Tabel 9.

Perhitungan Isoterm Langmuir Arang Batok Kelapa Berdiameter Mesh 12

\begin{tabular}{|c|c|c|c|c|c|c|c|c|c|}
\hline $\begin{array}{c}\text { Konsentrasi Air Limbah } \\
(\%) \\
\end{array}$ & Massa Adsorben (gr) & Co $(\mathrm{mg} / \mathrm{L})$ & $\mathrm{Ce}(\mathrm{mg} / \mathrm{L})$ & $\mathrm{V}(\mathrm{L})$ & $\begin{array}{c}\mathrm{m} \\
(\mathrm{mg} / \mathrm{L}) \\
\end{array}$ & $\mathrm{x}(\mathrm{mg} / \mathrm{L})$ & $\mathrm{x} / \mathrm{m}$ & $1 / \mathrm{Ce}$ & $1 /(\mathrm{x} / \mathrm{m})$ \\
\hline 100 & 12,5 & 32 & 21 & 1 & 12500 & 11 & 0,0009 & 0,05 & $1.136,36$ \\
\hline 75 & 12,5 & 32 & 21 & 1 & 12500 & 11 & 0,0009 & 0,05 & $1.136,36$ \\
\hline 50 & 12,5 & 32 & 15 & 1 & 12500 & 17 & 0,0014 & 0,07 & 735,29 \\
\hline
\end{tabular}

Hasil perhitungan yang diperoleh dari Tabel 7 hingga Tabel 9 dibuat grafik yang menghubungkan antara $1 / \mathrm{Ce}$ dan $1 /(\mathrm{x} / \mathrm{m})$. Grafik disajikan pada Gambar 3 hingga Gambar 5. Berdasarkan Gambar 3 hingga Gambar 5, hasil nilai regresi isoterm Langmuir arang batok kelapa berdiameter mesh 8, 10, dan 12 masingmasing sebesar 1. Nilai regresi yang didapat sangat baik, dimana nilai regresi yang baik adalah antara 0,9 hingga mendekati 1. Untuk memudahkan perbandingan, nilai regresi is oterm Langmuir dari setiap diameter mesh arang batok kelapa disajikan pada Tabel 10. Tabel 10 menunjukkan bahwa hasil nilai regresi yang mendekati satu dicapai oleh Isoterm Langmuir. Hasil ini menunjukkan data yang didapat pada hasil percobaan mendekati asumsi - asumsi pada Isoterm Langmuir sehingga untuk penentuan kapasitas adsorpsi arang batok kelapa akan digunakan persamaan Is oterm Langmuir.

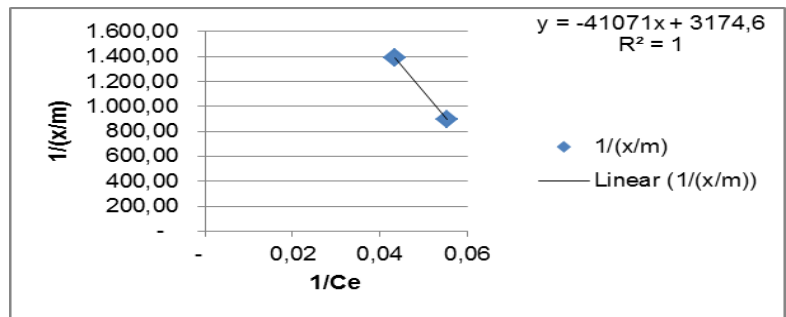

Gambar 3. Grafik Isoterm Langmuir Arang Batok Kelapa Berdiameter Mesh 8

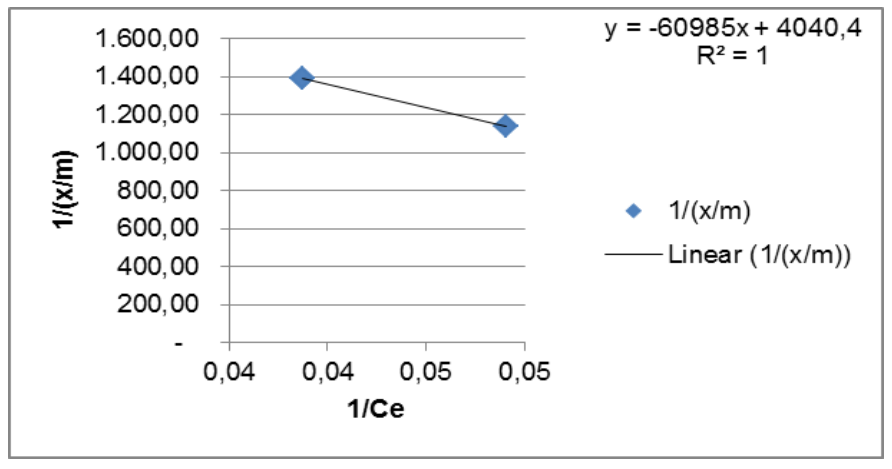

Gambar 4. Grafik Isoterm Langmuir Arang Batok Kelapa Berdiameter Mesh 10

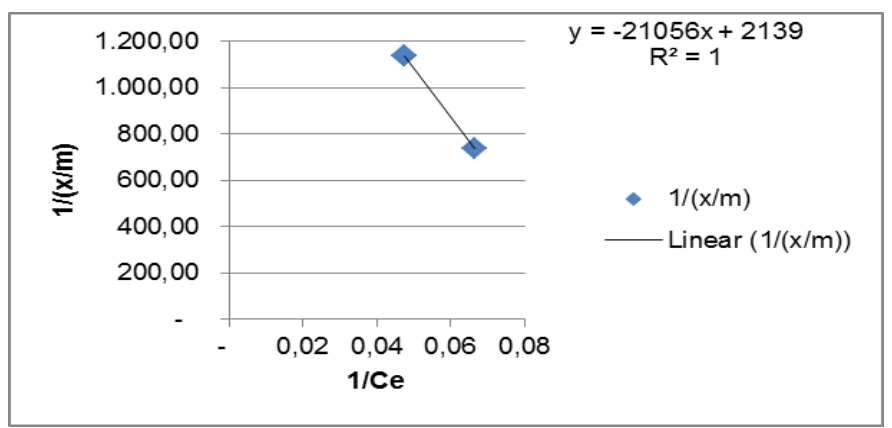

Gambar 5. Grafik Isoterm Langmuir Arang Batok Kelapa Berdiameter Mesh 12 
Tabel 10.

Nilai Regresi Isoterm Langmuir pada Parameter COD

\begin{tabular}{cc}
\hline \hline Diameter Mesh & $\begin{array}{c}\text { Nilai Regresi Isoterm } \\
\text { Langmuir }\end{array}$ \\
\hline 8 & 1 \\
10 & 1 \\
12 & 1 \\
\hline \hline
\end{tabular}

Setelah itu, dilakukan pengolahan hasil data yang didapat pada analisis adsorpsi dengan sistem batch. Berdasarkan Gambar 3 hingga Gambar 5, akan didapat persamaan linier dari is oterm Langmuir. Contoh dan hasil perhitungan dari setiap is oterm untuk mendapatkan nilai konstanta dan $\mathrm{x} / \mathrm{m}$ pada diameter mesh 8 disajikan pada Tabel 11 .

Tabel 11

Nilai $\mathrm{x} / \mathrm{m}$ menggunakan Isoterm Langmuir pada Parameter COD

\begin{tabular}{rrrccc}
\hline $\begin{array}{c}\text { Diameter } \\
\text { Mesh }\end{array}$ & intersep & slope & $\mathrm{K}_{\mathrm{L}}$ & $\mathrm{q}_{\mathrm{m}}$ & $\mathrm{x} / \mathrm{m}$ \\
\hline 8 & 50.000 & -862.500 & $-0,06$ & 0,00002 & 0,0001 \\
& & - & & & \\
10 & 100.000 & 2.012 .500 & $-0,05$ & 0,00001 & 0,0009 \\
12 & 11.111 & -145.833 & $-0,08$ & 0,00009 & 0,0002 \\
\hline
\end{tabular}

Diketahui pada diameter mesh 8:

Intersep $=50.000$

Slope $=-862.500$

$\mathrm{Co}=24 \mathrm{mg} / \mathrm{L}$

$\mathrm{Ce}=23 \mathrm{mg} / \mathrm{L}$

Sehingga

$\mathrm{q}_{\mathrm{m}}=1 /$ Intersep $=1 / 50.000=0,00002$

$\mathrm{K}_{\mathrm{L}}=1 /\left(\mathrm{q}_{\mathrm{m}} \mathrm{x}\right.$ slope $)=1 /(0,00002 \times(-862.500))=-0,06$

$\frac{x}{m}=\frac{q_{m} \times K_{L} \times C_{e}}{1+K_{L} \times C_{e}}=\frac{0,00002 \times(-0,06) \times 23}{1+(-0,06) \times 23}$

$\frac{x}{m}=0,00008 \frac{m g \text { adsorbat }}{m g \text { adsorben }}$

Berdasarkan hasil perhitungan pada Tabel 11, nilai adsorpsi isotermis yang didapat dengan menggunakan isoterm Langmuir pada diameter mesh 8, 10, 12 masing-masing sebesar
$1 \times 10^{-4} \mathrm{mg}$ adsorbat COD per $\mathrm{mg}$ adsorben, $9 \times 10^{-4} \mathrm{mg}$ adsorbat COD per mg adsorben, dan $2 \times 10^{-4} \mathrm{mg}$ adsorbat COD per mg adsorben.

\section{KESIMPULAN}

Kesimpulan dari penelitian ini yaitu nilai efisiensi removal adsorben arang batok kelapa untuk mengurangi konsentrasi zat pencemar air limbah industri pertambangan iodium pada skala laboratorium secara batch yaitu Parameter COD sebesar antara $28,13-53,13 \%$ dengan nilai $\mathrm{x} / \mathrm{m}$ untuk diameter mesh 8,10 , dan 12 masing-masing sebesar $1 \times 10^{-4} \mathrm{mg} / \mathrm{mg}, 9 \times 10^{-4} \mathrm{mg} / \mathrm{mg}$, dan 3 x $10^{-4} \mathrm{mg} / \mathrm{mg}$

\section{UCAPAN TERIMA KASIH}

Penulis F.S.A. mengucapkan terima kasih kepada Direktorat Jenderal Penguatan Riset dan Pengembangan, Kementerian Riset, Teknologi, dan Pendidikan Tinggi Republik Indonesia atas pemberian dukungan finansial penelitian melalui Program Kreativitas Mahasiswa tahun 2015. Penulis F.S.A juga mengucapkan terima kasih kepada Direktorat Jenderal Pembelajaran dan Kemahasiswaan, Kementerian Riset, Teknologi, dan Pendidikan Tinggi Republik Indonesia atas pemberian dukungan finansial pendidikan melalui Beasiswa Peningkatan Prestasi Akademik (PPA) tahun 2013-2014.

\section{DAFTAR PUSTAKA}

Pemerintah Provinsi Jawa Timur, "Peraturan Gubernur Jawa Timur Nomor 52 Tahun 2014 tentang Perubahan Atas Peraturan Gubernur Jawa Timur Nomor 72 Tahun 2013 tentang Baku Mutu Air Limbah Bagi Industri dan/atau Kegiatan Usaha Lainnya," 2014.

P. Atkins, Kimia Fisika, 4th ed. 1999.

] Degremont, Water Treatment Handbook. Paris: Lavoisier, 1991.

A. Yuniarto, "Studi Kemampuan Batu Bara Untuk Menurunkan Konsentrasi Surfaktan Dalam Larutan Deterjen Dengan Proses Adsorpsi," Surabaya, 1999.

[5] R. Jannatin, "Uji Kemampuan Adsorpsi Arang Batok Kelapa Untuk Mereduksi Warna dan Permanganat Value Dari Limbah Cair Industri Batik," Surabaya, 2011. 